\title{
Vascular endothelial growth factor transgene expression in cell-transplanted hearts
}

Terrence M. Yau, MD, MSc

Guangming Li, MD

Richard D. Weisel, MD

Adili Reheman, MD

Zhi-Qiang Jia, MD

Donald A. G. Mickle, MD

Ren-Ke Li, MD, PhD

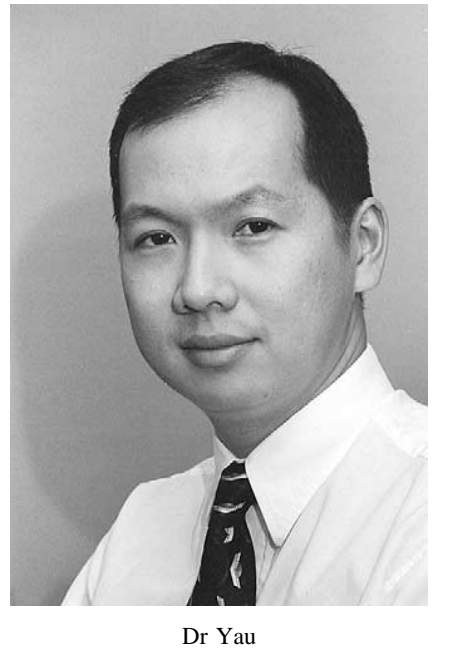

From the Division of Cardiovascular Surgery, Toronto General Hospital, University Health Network, Department of Surgery, University of Toronto, and the Heart and Stroke Foundation/Richard Lewar Centre of Excellence, Toronto, Ontario, Canada.

Supported by a grant from the Heart and Stroke Foundation of Ontario (NA4873) to Terrence M. Yau.

Received for publication July 23, 2003; revisions requested Sept 25, 2003; accepted for publication Sept 30, 2003.

Address for reprints: Terrence M. Yau, MD, MSc, FRCSC, Division of Cardiovascular Surgery, Toronto General Hospital, University Health Network, 13EN-239, 200 Elizabeth St, Toronto, Ontario, Canada, M5G 2C4 (E-mail: terry.yau@utoronto.ca).

J Thorac Cardiovasc Surg 2004;127:1180-7

$0022-5223 / \$ 30.00$

Copyright $\odot 2004$ by The American Association for Thoracic Surgery

doi:10.1016/j.jtcvs.2003.09.052
Objective: We evaluated the effect of transplanted cell type, time, and region of the heart on transgene expression to determine the potential of combined gene and cell delivery for myocardial repair.

Methods: Lewis rats underwent myocardial cryoinjury 3 weeks before transplantation with heart cells (a mixed culture of cardiomyocytes, smooth muscle cells, endothelial cells and fibroblasts, $\mathrm{n}=13$ ), vascular endothelial growth factortransfected heart cells $(n=13)$, skeletal myoblasts $(n=13)$, vascular endothelial growth factor-transfected skeletal myoblasts $(\mathrm{n}=13)$, or medium (control, $\mathrm{n}=12$ ). Vascular endothelial growth factor expression in the scar, border zone, and normal myocardium was evaluated at 3 days and at 1, 2, and 4 weeks by means of quantitative polymerase chain reaction. Transplanted cells and vascular endothelial growth factor protein were identified immunohistologically on myocardial sections.

Results: Vascular endothelial growth factor levels were very low in control scars but increased transiently after medium injection. Transplantation with heart cells and skeletal myoblasts significantly increased vascular endothelial growth factor expression in the scar and border zone. Transplantation of vascular endothelial growth factor-transfected heart cells and vascular endothelial growth factor-transfected skeletal myoblasts further augmented vascular endothelial growth factor expression, resulting in 4- to 5-fold greater expression of vascular endothelial growth factor in the scar at 1 week. Peak vascular endothelial growth factor expression was greater and earlier in vascular endothelial growth factor-transfected heart cells than in vascular endothelial growth factor-transfected skeletal myoblasts. Vascular endothelial growth factor was primarily expressed by the transplanted cells. Some of the transplanted heart cells and vascular endothelial growth factor-transfected heart cells were identified in the endothelial layer of blood vessels in the scar.

Conclusions: Transplantation of heart cells and skeletal myoblasts induces vascular endothelial growth factor expression in myocardial scars and is greatly augmented by prior transfection with a vascular endothelial growth factor transgene. Vascular endothelial growth factor expression is limited to the scar and border zone for 4 weeks. Both heart cells and skeletal myoblasts may be excellent delivery vehicles for cell-based myocardial gene therapy.

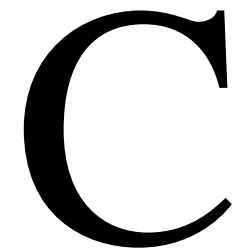

ell transplantation may be a novel therapeutic option for myocardial repair in hearts with postinfarction congestive heart failure, unreconstructable coronary atherosclerosis, or cardiomyopathy. ${ }^{1-6}$ We have previously studied the angiogenic effect of transplantation of endothelial cells ${ }^{7}$ or of a mixed culture of heart cells (predominantly cardiomyocytes, with smaller proportions of endothelial cells, smooth muscle cells, and fibroblasts). ${ }^{8}$ When these cells were transfected with 
vascular endothelial growth factor (VEGF) 165 ex vivo and then transplanted into scarred rat hearts, regional blood flow and vascular densities were significantly greater than those observed after transplantation of unmodified cells or of culture medium alone. Ex vivo modification of cells before transplantation may therefore have the potential to enhance survival of the transplanted cells and modify their effect on angiogenesis, matrix remodeling, or restoration of function. However, the duration of transgene expression after transplantation is unknown and is likely to differ from that observed after gene transfer alone by means of intramyocardial injection of adenoviral vectors. Long-term or uncontrolled expression of angiogenic transgenes has been associated with angioma formation. ${ }^{9}$ Optimal transgene expression in transplanted cells would therefore be transient but of sufficient duration to ensure maximal therapeutic effect. It would also be limited spatially to the zone to which the transplanted cells were delivered to prevent undesirable angiogenesis in normal myocardium.

In this series of experiments, we hypothesized that a $V E G F$ transgene would be expressed only transiently in cells transplanted into scarred rat hearts and that this VEGF expression would be limited to the zone of transplantation. We also evaluated the effect of 2 different cell types to determine whether there were cell-specific differences in transgene expression that might influence the suitability of varying cell types for future therapies.

\section{Methods}

\section{Animals and Experimental Model}

Animals were syngeneic adult Lewis rats (body weight of 225-250 $\mathrm{g}$ for female rats and 250-300 $\mathrm{g}$ for male rats; Charles River Canada Inc, Quebec, Canada). All procedures were approved by the Animal Care Committee of the University Health Network and conformed to the guidelines in the "Guide to the Care and Use of Laboratory Animals" prepared by the National Research Council and published by the National Academy Press.

A large transmural scar was created in the left ventricular (LV) free wall of rat hearts by means of a cryoinjury technique, as previously described. ${ }^{8}$ Briefly, through a left lateral thoracotomy, the LV free wall was exposed, and cryoinjury was performed by means of 12 one-minute applications of an $8 \times 10$-mm elliptical metal probe cooled to $-196^{\circ} \mathrm{C}$ by means of immersion in liquid nitrogen. After recovery, the cryoinjured rats were randomly divided into 5 experimental groups: control, injected with culture medium alone (control, $\mathrm{n}=12$ ), transplantation with a mixed culture of unmodified heart cells (HC group; $\mathrm{n}=13$ ), transplantation with VEGF-transfected heart cells ( $\mathrm{HC}+$ group; $\mathrm{n}=13$ ), transplantation with unmodified skeletal myoblasts (Sk group; $\mathrm{n}=$ 13), or transplantation with VEGF-transfected skeletal myoblasts $(\mathrm{Sk}+$ group; $\mathrm{n}=13)$.

\section{Cell Isolation and Culture}

A mixed primary culture of cardiomyocytes, smooth muscle cells, endothelial cells, and fibroblasts was isolated from the left ventri- cles of donor rats, as previously described. ${ }^{8}$ The cultured cells were depleted of fibroblasts by means of a preplating technique and then maintained in Iscove's modified Dulbecco's medium (IMDM) containing 10\% fetal bovine serum (FBS) for 5 to 7 days before transfection and transplantation. In a subset of plates, $69 \%$ of cells stained positively for myosin heavy chain and were assumed to be cardiomyocytes, $14 \%$ of cells stained positively for $\alpha$-smooth muscle actin and were assumed to be smooth muscle cells, and $12 \%$ of cells stained positively for Factor VIII and were assumed to be endothelial cells. The remaining cells were assumed to be fibroblasts.

Primary skeletal myoblasts were isolated and cultured by means of a modified, single muscle fiber culture technique. ${ }^{10}$ Briefly, $3 \mathrm{~g}$ of muscle from the quadriceps femoris muscle of adult Lewis rats underwent enzymatic digestion with protease and type I collagenase (Sigma, St Louis, Mo) before isolation and resuspension of single intact muscle fibers in IMDM containing $10 \%$ FBS. After preplating, single skeletal muscle fibers were plated onto laminin-coated plates (Becton Dickinson Labware, Bedford, Mass). Skeletal myoblasts dissociated from the muscle fibers, attached to the plate, and were allowed to proliferate for 48 to 72 hours, as the original muscle fibers underwent cell death and lysis. The skeletal myoblasts were maintained in IMDM containing $10 \%$ FBS for a further 5 to 7 days and then transfected before fusion and myotube formation.

\section{Cell Transfection}

Skeletal myoblasts and heart cells were transfected in 100-mm dishes at $60 \%$ to $70 \%$ confluence. Cells were transfected ex vivo by means of a lipid-based technique, with a plasmid encoding VEGF165 (pCEP4-VEGF), as previously described. ${ }^{8}$ Transfection efficiencies were monitored in a subset of plates by means of cotransfection with pEGFP-N2 (BD Biosciences Clontech, Palo Alto, Calif), a plasmid expressing green fluorescence protein. Cells were incubated with the transfection reagents for 24 hours before transplantation.

\section{Bromodeoxyuridine Prelabeling}

A subset of the plates ( 1 of every 4 plates) of skeletal myoblasts and heart cells was prelabeled with bromodeoxyuridine (BrdU) 2 days before transplantation and 1 day before transfection (when applicable) to facilitate identification of transplanted cells in the recipient hearts. ${ }^{8}$ Preliminary evaluation of BrdU uptake efficiency in these plates of cells indicated that approximately $60 \%$ of the cultured cells stained positively for BrdU. In histologic sections of the rat hearts in the transplanted groups, a monoclonal antibody against BrdU was used to identify the transplanted cells within the recipient hearts.

\section{Cell Transplantation}

Rats underwent cell transplantation 3 weeks after cryoinjury of the LV free wall. VEGF-transfected or VEGF-untransfected heart cells or skeletal myoblasts were detached from culture dishes with trypsin, centrifuged, and resuspended in serum-free medium. After induction of general anesthesia, rat hearts were exposed through a midline sternotomy. Three million cells in $0.05 \mathrm{~mL}$ of serum-free medium were injected at multiple points into the center of the cryoinjury-induced LV scar with a tuberculin syringe. The same 
volume of culture medium without cells was injected into the scars of control rats.

Rats were put to death, and the hearts were excised 3 days ( $\mathrm{n}$ $=15), 1$ week $(n=15), 2$ weeks $(n=15)$, and 4 weeks $(n=19)$ after cell transplantation. The atria and the right ventricular free wall were excised, leaving the left ventricle, which was divided into the scar zone (consisting of the transmural scar), the border zone (partial-thickness scar containing both fibrous tissue and surviving muscle), and the normal area. A portion of each zone was fixed in formalin for histologic evaluation, and the rest of the tissue was frozen in liquid nitrogen for analysis of gene expression.

\section{RNA Isolation and Reverse Transcription}

Myocardial specimens were snap-frozen in liquid nitrogen and powdered. A portion of each specimen was used immediately for total RNA isolation, whereas the remainder was stored at $-80^{\circ} \mathrm{C}$ for subsequent analysis of protein levels. Total RNA was isolated with TRIzol RNA extraction reagents (Invitrogen Corp, Carlsbad, Calif), according to the manufacturer's specifications. Messenger RNA in this specimen was reverse transcribed to single-strand cDNA with SuperScript II reverse transcriptase (Invitrogen Corp). Briefly, $10 \mu \mathrm{g}$ of total RNA was mixed with $1 \mu \mathrm{g}$ of oligo (dT) 20 -mer at $65^{\circ} \mathrm{C}$ and incubated for 5 minutes. The sample was placed on ice, and $4 \mu \mathrm{L}$ of $5 \times$ first-strand buffer, $2 \mu \mathrm{L}$ of 10 $\mathrm{mmol} / \mathrm{L}$ dithiothreitol, 40 units of RNase inhibitor, and 400 units of SuperScript II reverse transcriptase were added to a $20-\mu \mathrm{L}$ final reaction volume. The mixture was incubated at $42^{\circ} \mathrm{C}$ for $60 \mathrm{~min}-$ utes, followed by enzyme inactivation at $70^{\circ} \mathrm{C}$ for 15 minutes. The reverse transcribed cDNA was stored at $-20^{\circ} \mathrm{C}$ for later use.

\section{Quantitation of VEGF mRNA by Means of Real-Time Polymerase Chain Reaction}

Quantitation of VEGF mRNA expression was carried out by means of real-time polymerase chain reaction (PCR) on the 9700 HT System (Applied Biosystems Inc, Foster City, Calif). Two pairs of specific PCR primers were designed on the basis of VEGF sequences from the GeneBank (National Center for Biotechnology Information) to accurately evaluate the molecular weight of the PCR products. One primer (antisense, 5'-TGAAGGTCGGAGTCAACGGATTT-GGT-3'; sense, 5'-CATGTGGGCCATGAGGTCCACCAC-3') generated a 277-bp sequence, and the other (antisense, 5'-TCATGGTTGTCTATCAGCGCAG-3'; sense, 5'GCACACAG-GATGGCTTGAAGAT-3') generated a 107-bp fragment located within the 277-bp sequence.

Standard PCR was first performed with these 2 primers by using the single-strand cDNA from the sample as a template. Gel electrophoresis confirmed that the PCR products comprised a single band of the correct size. This band was excised, and the PCR product was purified from the gel and then sequenced to confirm its identity as the VEGF coding sequence. The purified 277-bp product was quantitated spectrophotometrically for use as a standard for subsequent real-time PCR assays.

Real-time PCR was performed on experimental samples and the VEGF standards by using the 107-bp VEGF primers with the Master Mix SYBR Green I Kit (Applied Biosystems Inc, Foster City, Calif) by using 3-fold serial dilutions of VEGF standards in dd-water to generate standards ranging from 1500 to $0.23 \mathrm{pg}$. cDNA samples from the experimental animals were diluted 200- fold, and $5 \mu \mathrm{L}$ of each standard or sample was transferred to a 96-well PCR plate. Each assay was performed in duplicate, and 5 $\mu \mathrm{L}$ of dd-water was assayed as a no-template control. Five microliters of a 5 pmol $V E G F$ sense and antisense primer mixture (producing a 107-bp product) and $10 \mu \mathrm{L}$ of Master SYBR Green I Mix were added to each well. The reaction sequence included stabilization for 2 minutes at $50^{\circ} \mathrm{C}$ and denaturation for 10 minutes at $95^{\circ} \mathrm{C}$ before 40 cycles of denaturation for 15 seconds at $95^{\circ} \mathrm{C}$, annealing for 15 seconds at $60^{\circ} \mathrm{C}$, extension for 1 minute at $72^{\circ} \mathrm{C}$, and dissociation for 15 seconds at $95^{\circ} \mathrm{C}, 15$ seconds at $65^{\circ} \mathrm{C}$, and 15 seconds at $95^{\circ} \mathrm{C}$. Real-time PCR data were analyzed with SDS 2.1 software (Applied Biosystems Inc, Foster City, Calif). Results are reported as molecular copies of $V E G F$ per microgram of total RNA.

\section{Quantitation of VEGF Protein}

VEGF protein in the scar, border zone, and normal myocardium was quantitated by means of chemiluminescent slot blot analysis (MiniFold II; Schleicher \& Schuell Inc, Keene, NH), as previously described. $^{8}$

\section{Histologic and Immunohistochemical Assays}

Myocardial specimens were fixed in formalin, embedded in paraffin, and sectioned into 6- $\mu$ m-thick slices. One slide of each sample was stained with hematoxylin and eosin for morphologic evaluation of the scar and transplanted cells. Immunohistochemical staining with monoclonal antibodies directed against BrdU, Factor VIII, or VEGF was performed to localize the transplanted cells, VEGF protein, and vascular spaces. Slides were deparaffinized in xylene and rehydrated in graded ethanol, immersed in $3 \% \mathrm{H}_{2} \mathrm{O}_{2}$ in $70 \%$ methanol to inhibit endogenous peroxidase, and incubated in $0.2 \%$ of Triton X-100. Nonspecific protein binding was blocked with $2 \%$ normal goat serum and $150 \mu \mathrm{L}$ of primary antibodies against BrdU (1:2000), Factor VIII (1:1000), VEGF (1:3000), or phosphate-buffered saline (PBS; as a negative control) was added before incubation at $4{ }^{\circ} \mathrm{C}$ overnight. Slides were washed to remove unbound primary antibodies, and a biotin-labeled secondary antibody (1:2500; BioRad Laboratories, Richmond, Calif) was added. After washing, sections were incubated with an avidinbiotin complex conjugated with peroxidase. Visualization was performed with a diaminobenzidine solution. Cellular nuclei were counterstained with hematoxylin for 1 minute, and the samples were then covered with crystal mounts and photographed.

VEGF protein and the transplanted cells were also identified and localized by means of immunohistochemical double staining with a laser confocal microscopy system (Bio-Rad, Richmond, Calif), according to the manufacturer's protocols (Molecular Probe Inc, Eugene, Ore). Briefly, the slides were treated with $3 \% \mathrm{H}_{2} \mathrm{O}_{2}$ in $70 \%$ methanol, incubated in $0.2 \%$ Triton X-100, and blocked with $2 \%$ normal goat serum after rehydration. Slides were incubated with fluorescein isothiocyanate-labeled anti-BrdU antibodies (1:100), phycoerythrin-labeled anti-VEGF antibodies (1:100), or both overnight at $4^{\circ} \mathrm{C}$. Unbound antibodies were washed away with PBS. Slides were treated with $10 \mathrm{mg} / \mathrm{mL}$ RNase (Qiagen, Mississauga, Ontario, Canada) for 30 minutes at room temperature, washed with PBS, and incubated for 5 minutes in 4,6diamino-2-phenylindole (DAPI) diluted 1:300 in PBS to stain both host and donor cell nuclei. The fluorescein isothiocyanate, phyco- 
erythrin, and DAPI fluorescent emissions were detected by using laser detectors at $488 \mathrm{~nm}, 575 \mathrm{~nm}$, and $461 \mathrm{~nm}$ wavelengths, respectively, and observable under confocal microscopy as green, red, and blue fluorescent signals.

\section{Statistical Analysis}

To evaluate the determinants of VEGF expression levels, we first analyzed the effect of group, time, and location by means of analysis of variance with SAS statistical software (Cary, NC). Both main effects and interactive effects (group $\times$ time, group $\times$ location, time $\times$ location, and group $\times$ time $\times$ location) were evaluated.

A second analysis was performed on the 4 cell-transplanted groups to statistically evaluate the effect of VEGF transfection and cell type rather than group assignment in general, evaluating the effects of VEGF transfection (yes-no), cell type (heart cellsskeletal myoblasts), time, and location by means of analysis of variance. Again, main effects and all 2-way interactive effects (VEGF $\times$ cell type, VEGF $\times$ time, VEGF $\times$ location, cell type $\times$ time, cell type $\times$ location, and time $\times$ location) were modeled. Nonsignificant interactive effects were discarded, and the final model included only the 4 main effects and the statistically significant interactive effects.

Because of the large number of data points incorporated in this analysis and the multiple comparisons that could theoretically be performed (between 5 groups, 4 time points, and 3 regions), we deliberately avoided statistical analysis of subsets of these data (eg, assigning a $P$ value to the comparison of the $\mathrm{HC}+$ group with the other groups at the 1-week time point in the scar region). The very large number of potential subset analyses of this type would have entailed a very high probability of a type I error. Instead, we chose to present the data graphically, depicting means and SDs, to visually depict obvious differences or lack of differences in the context of the overall analysis of main and interactive effects described previously. In addition, overall effects of a specific factor (eg, the effect of experimental group across all time points and all zones studied) were subjected to the Duncan multiple-range test to identify differences in $V E G F$ mRNA levels related to a specific predictor.

\section{Results}

\section{VEGF Expression: Overall Effects of Group, Time,} and Zone

$V E G F$ mRNA levels in the scar, border zone, and normal area at 3 days and 1,2, and 4 weeks are depicted in Figure 1 for the 4 cell-transplanted groups and the control group. As anticipated, all overall main effects were highly significant (group, time, and zone effects: all $P<.0001$ ). All interactive effects were also highly significant (group $\times$ time, group $\times$ location, time $\times$ location, and group $\times$ time $\times$ location effects: all $P<.0001$ ). Overall $V E G F$ mRNA and protein levels were significantly higher in the $\mathrm{HC}+$ and $\mathrm{Sk}+$ groups than in the $\mathrm{HC}$ and Sk groups $(P<.05)$, which were again greater than those in the control group $(P<.05)$. Overall $V E G F$ mRNA and protein levels were significantly higher in the scar and border zone than in the normal myocardium $(P<.05)$.
When the 4 cell-transplanted groups were analyzed without the control group, to determine the effects of cell type and VEGF transfection on VEGF expression, the effects of transfection, time, and zone were all highly significant $(P<$ $.0001)$, whereas the effect of cell type was not $(P=.8)$. All interactive effects except transfection $\times$ cell type $(P=.13)$ were significant $(P<.05)$.

\section{VEGF Expression: Effect of Cell Transplantation Alone}

$V E G F$ mRNA and protein levels in the scars of control rat hearts injected only with medium were extremely low (Figure 1). VEGF mRNA expression in control rats was slightly greater at 3 days than at 1,2 , or 4 weeks. Levels in control hearts at 1,2 , and 4 weeks were similar. In hearts transplanted with unmodified heart cells or skeletal myoblasts, $V E G F$ mRNA expression was greater than that in control rats at 3 days and 1 and 2 weeks (Figure 1). Peak VEGF mRNA expression in hearts transplanted with unmodified cells (heart cells or skeletal myoblasts) occurred at 3 days in both groups. VEGF mRNA expression was greater in the scar than in the border zone at 3 days and 1 and 2 weeks in the HC and Sk groups, whereas expression levels in normal myocardium in the $\mathrm{HC}$ and Sk groups were similar to those in the control group at all time points studied. By 4 weeks, $V E G F$ mRNA expression had decreased in the scar and border zones of the hearts of the $\mathrm{HC}$ and Sk groups to levels that were similar to those observed in the control group.

\section{VEGF Expression: Effect of Ex Vivo Transfection with VEGF}

Prior ex vivo transfection with a $V E G F$ transgene in the $\mathrm{HC}+$ and $\mathrm{Sk}+$ groups was associated with dramatically increased levels of $V E G F \mathrm{mRNA}$ and protein expression in the scars and border zones of these hearts compared with $\mathrm{HC}$, Sk, or control hearts at 3 days and 1 and 2 weeks (Figure 1). The overall effect of VEGF transfection on $V E G F$ mRNA and protein levels in the cell-transplanted groups was highly significant $(P<.0001)$. VEGF mRNA and protein expression in the $\mathrm{HC}+$ and $\mathrm{Sk}+$ groups was substantially greater in the scar than in the border zone at 3 days and 1 and 2 weeks. By 4 weeks, VEGF mRNA and protein levels had decreased and were similar to those in the control group. VEGF mRNA levels in the normal myocardium were similar in all groups at all times.

\section{VEGF Expression: Effect of Cell Type}

Peak VEGF mRNA expression in the scar areas of the $\mathrm{HC}+$ hearts was observed at 3 days compared with 7 days for the $\mathrm{Sk}+$ hearts (Figure 1, $A$ and $B$ ). Maximum $V E G F$ mRNA levels appeared to be greater in the scar areas of the $\mathrm{HC}+$ hearts (at 3 days) than in the $\mathrm{Sk}+$ hearts (at 1 week). In contrast, VEGF mRNA expression in the border zone appeared to be greater in the $\mathrm{Sk}+$ hearts at 1 week than in the 

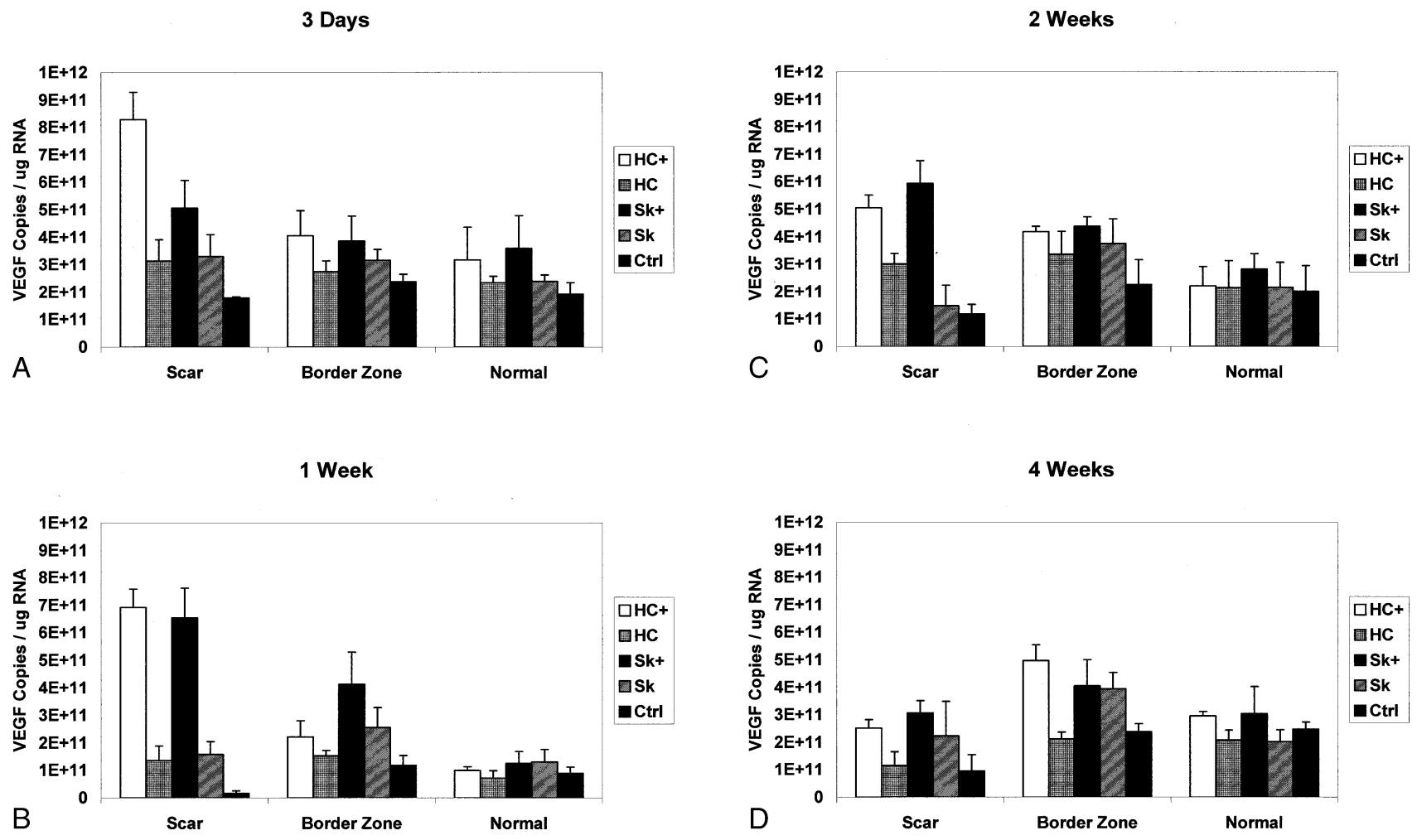

Figure 1. VEGF mRNA expression in rat hearts transplanted with heart cells (HC), VEGF-transfected heart cells $(H C+)$, skeletal myoblasts (Sk), VEGF-transfected skeletal myoblasts $(S k+)$, or medium alone (Ctrl) evaluated by means of quantitative PCR at 3 days (A), 1 week (B), 2 weeks (C), or 4 weeks (D). Transplantation with heart cells and skeletal myoblasts induced greater VEGF expression than that of the control hearts, and VEGF mRNA levels in $\mathrm{HC}+$ and Sk+ hearts were markedly increased over those in the HC and Sk groups. VEGF expression was greatest in the scar, intermediate in the border zone, and did not differ from control values in the normal myocardium. Expression was limited to 4 weeks.

$\mathrm{HC}+$ hearts (Figure 1,B). Although the overall effect of cell type on VEGF mRNA expression in cell-transplanted hearts was not significant $(P=.8)$, significant interactive effects of cell type $\times$ time $(P=.02)$ and cell type $\times$ zone $(P=.01)$ were noted.

\section{Colocalization of VEGF Expression with Transplanted Cells}

Transplanted cells were localized within the myocardial scar in all cell-transplanted hearts by means of immunohistochemical staining with monoclonal antibodies directed against BrdU (Figure 2, A), as well as by means of confocal microscopy of sections stained with both green fluorescence-tagged antibodies against BrdU and blue fluorescencetagged DAPI labeling of all cell nuclei (Figure 2, B). Photomicrographs of hearts stained with green fluorescencetagged antibodies against BrdU and red fluorescencetagged antibodies against VEGF demonstrated that VEGF was being expressed in the transplanted cells (Figure 2,C). The degree of staining for VEGF was qualitatively more intense in the $\mathrm{HC}+$ and $\mathrm{Sk}+$ groups at 3 days and 1 week, which is consistent with the real-time PCR observations.

\section{Angiogenesis}

Vascular spaces lined with Factor VIII-positive cells were observed in the scars and border zones of all rat hearts but were qualitatively fewer in the control hearts, intermediate in the $\mathrm{HC}$ and Sk hearts, and greatest in the $\mathrm{HC}+$ and $\mathrm{Sk}+$ hearts. BrdU-positive endothelial cells were identified in blood vessels within the scars of $\mathrm{HC}+$ hearts and, to a lesser extent, within the scars of $\mathrm{HC}$ hearts (Figure 3 ) but were not apparent in the other groups.

\section{Discussion}

In this study our quantitative PCR results indicated that $V E G F$ expression in the hearts transplanted with $V E G F$ transfected heart cells and $V E G F$-transfected skeletal myoblasts was dramatically greater than in hearts transplanted with unmodified heart cells and skeletal myoblasts. In all 

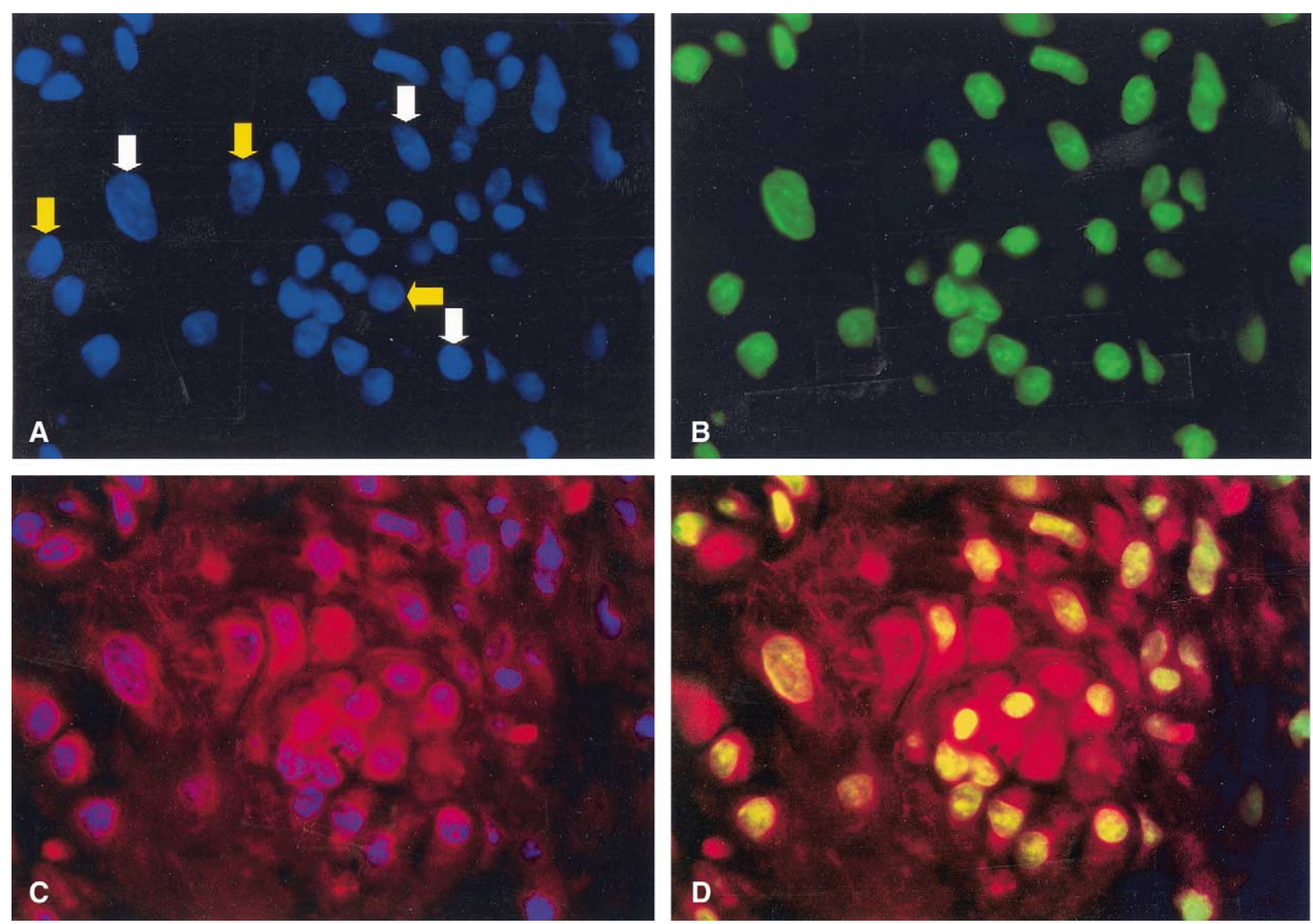

Figure 2. Laser confocal micrographs of serial sections of the scar of a rat heart transplanted with VEGFtransfected heart cells $(\mathrm{HC}+$ ) after DAPI (blue) staining of all cell nuclei (A), BrdU (green) staining of transplanted cell nuclei (B), DAPI (blue) staining of all cell nuclei and VEGF (red) staining (C), or BrdU (yellow) staining of transplanted cell nuclei and VEGF (red) staining (D). (Original magnification 1000×.) DAPI-positive and BrdUpositive nuclei (white arrows) represent transplanted cells. DAPI-positive and BrdU-negative nuclei (yellow arrows) might represent either BrdU-unlabeled transplanted cells or host cells. Cytoplasmic VEGF protein (red) surrounds both the BrdU-positive nuclei and the smaller number of BrdU-negative nuclei.

cell-transplanted hearts, however, VEGF expression was temporally limited to a 4-week period after transplantation. We deliberately used a technique of gene transfer in which transient rather than long-term expression would be anticipated. Because persistent or uncontrolled VEGF expression might result in excessive angiogenesis or angioma formation, ${ }^{9}$ a limited duration of transgene expression may provide greater safety while still achieving the desired angiogenesis. Histologic examination did not reveal any evidence of angioma formation as a result of this gene delivery strategy at the time points studied.

The 4-week duration of transgene expression observed with these ex vivo transfected cells compares with the approximately 1- to 4-week duration of expression reported after adenoviral transfection techniques of direct gene transfer without cell transplantation. Host immune responses to the adenoviral vectors are thought to limit the duration of expression in such delivery strategies. ${ }^{11-13}$ In these experi-

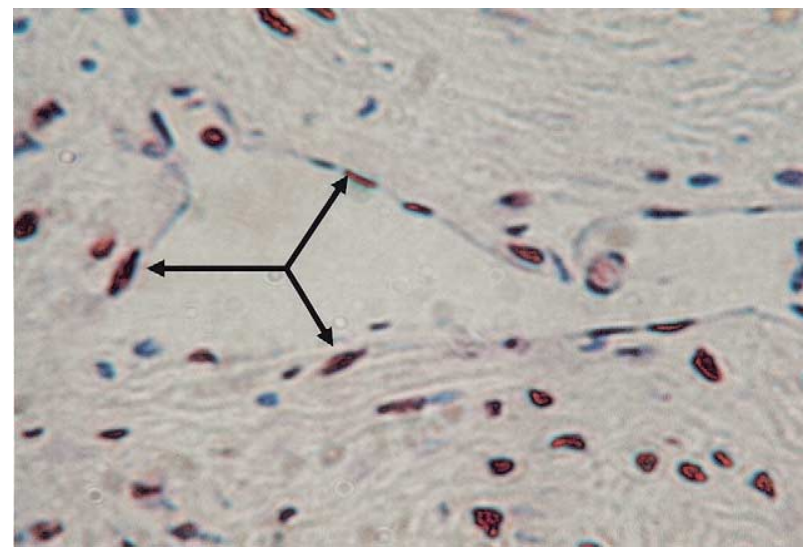

Figure 3. Conventional light photomicrograph of the scar of a rat heart transplanted with VEGF-transfected heart cells $(\mathrm{HC}+)$ after immunostaining for BrdU. BrdU-positive transplanted cells (arrows) are observed in the endothelial cell layer of this capillary. (Original magnification $600 \times$.) 
ments we attempted to minimize the immune response to the transplanted cells by using syngeneic donor cells. No immunosuppressive therapy was administered to these rats, and we did not observe any histologic evidence of an immune response, such as a lymphocytic infiltrate. Such an immune response could, however, occur because of the transplanted cells, the technique of DNA transfer, or an immunogenic transgene product. We used a lipid-based, rather than viral, technique of DNA transduction to minimize potential host responses to viral proteins. Obviously, if this technique of ex vivo gene transfer before cell transplantation resulted in increased immunogenicity and therefore led to the eventual rejection of the transplanted cells, it would be of very limited utility. Care will therefore have to be taken in future studies to select gene products that are not significantly antigenic.

Suzuki and colleagues ${ }^{14}$ have previously reported that skeletal myoblasts transduced with VEGF through hemagglutinating virus of Japan liposome and transplanted into the border zone of a circumflex artery infarct resulted in increased VEGF expression in whole LV specimens. They did not, however, examine the spatial distribution of this VEGF expression to determine whether inappropriate expression occurred in normal myocardium. In our current study enhanced VEGF expression was spatially limited to the scars and border zones of cell-transplanted hearts, regardless of the presence or absence of prior transfection with a VEGF transgene. In all cell-transplanted groups and at all times, VEGF levels in the scars were higher than levels in the border zones. VEGF mRNA levels in the normal myocardium were similar to control levels in all groups at all time points. At thoracotomy, donor cells were injected into multiple sites in what appeared visually to be the center of the scar and its immediate surroundings. At the time of histologic evaluation, transplanted cells were observed throughout the scar and, to a lesser degree, in the border zone. The local prevalence of the transplanted cells appeared to correlate with the level of VEGF expression, and confocal microscopy confirmed that VEGF expression was localized to the transplanted cells. It is likely, however, that a low level of VEGF expression will take place in host cells that have absorbed VEGF-coding plasmids from donor cells that die and undergo lysis after transplantation.

Interestingly, we also observed a low but distinct increase in VEGF expression at 3 days in control hearts in which only serum-free culture medium, without cells, was injected. This likely represents a response to the local trauma of injection and may be analogous to the angiogenic response to mechanical or laser perforation of the myocardium. Under the conditions used in this study, however, this response was dwarfed by the effects of cell transplantation and of $V E G F$ gene transfer.
In this study peak $V E G F$ expression occurred earlier in $\mathrm{HC}+$ hearts than in $\mathrm{Sk}+$ hearts (3 days vs 7 days), and peak $V E G F$ levels were greatest in $\mathrm{HC}+$ hearts. In contrast, $V E G F$ levels in the border zone at 1 week appeared to be greater with $\mathrm{Sk}+$ than $\mathrm{HC}+$ hearts. Although the degree of angiogenesis induced by means of cell transplantation may represent an important determinant of transplanted cell survival and ultimate efficacy, it is unclear as to whether the differences in peak VEGF expression observed between heart cells and skeletal myoblasts in this study will have a significant effect on cell survival. Heart cells and skeletal myoblasts may also have differential susceptibilities to the ischemic conditions in the scar or differential survival rates after transplantation for other reasons, and the importance of this finding therefore remains unknown.

Histologic evaluation revealed BrdU-positive cells in the endothelial layer of capillaries and arterioles in the scars and border zones of $\mathrm{HC}$ and $\mathrm{HC}+$ hearts, but not in the other groups. These cells are probably derived from the endothelial cell population in the mixed cultures of heart cells and $V E G F$-transfected heart cells used in this study. We did not expect, and did not observe, BrdU-positive endothelial cells in the Sk and $\mathrm{Sk}+$ groups.

In summary, our study demonstrated that ex vivo transfection of either a mixed culture of heart cells or of skeletal myoblasts with a $V E G F$-encoding plasmid was associated with dramatically increased levels of VEGF mRNA expression. This $V E G F$ expression occurred primarily in transplanted cells and was spatially limited to the scars and border zones of the rat hearts and temporally limited to a 4-week duration. These patterns of transgene expression suggest that both heart cells and skeletal myoblasts may be appropriate delivery vehicles for therapeutic transgenes. We are currently evaluating the effect of this $V E G F$ transgene on survival of the transplanted cells, the durability of the angiogenic response, and its safety profile over a longer follow-up period. Transplantation of cells transfected with multiple genes to promote angiogenesis, to enhance integration with host cells, ${ }^{15}$ or to minimize apoptosis ${ }^{16}$ may ultimately prove to be the most promising therapeutic application of cell transplantation.

\section{References}

1. Zibaitis A, Greentree D, Ma F, Marelli D, Duong M, Chiu RC. Myocardial regeneration with satellite cell implantation. Transplant Proc. 1994;26:3294.

2. Van Meter CH Jr, Claycomb WC, Delcarpio JB, Smith DM, deGruiter H, Smart F, et al. Myoblast transplantation in the porcine model: a potential technique for myocardial repair. J Thorac Cardiovasc Surg. 1995;110:1442-8.

3. Li RK, Jia ZQ, Weisel RD, Mickle DA, Zhang J, Mohabeer MK, et al. Cardiomyocyte transplantation improves heart function. Ann Thorac Surg. 1996;62:654-60.

4. Li RK, Weisel RD, Mickle DA, Jia ZQ, Kim EJ, Sakai T, et al. Autologous porcine heart cell transplantation improved heart function 
after a myocardial infarction. J Thorac Cardiovasc Surg. 2000;119: $62-8$.

5. Yau TM, Tomita S, Weisel RD, Jia ZQ, Tumiati LC, Mickle DA, et al. Beneficial effect of autologous cell transplantation on infarcted heart function: comparison between bone marrow stromal cells and heart cells. Ann Thorac Surg. 2003;75:169-76.

6. Yoo KJ, Li RK, Weisel RD, Mickle DA, Jia ZQ, Kim EJ, et al. Heart cell transplantation improves heart function in dilated cardiomyopathic hamsters. Circulation. 2000;102(suppl III):III204-9.

7. Kim EJ, Li RK, Weisel RD, Mickle DA, Jia ZQ, Tomita S, et al. Angiogenesis by endothelial cell transplantation. $J$ Thorac Cardiovasc Surg. 2001;122:963-71.

8. Yau TM, Fung K, Weisel RD, Fujii T, Mickle DA, Li RK. Enhanced myocardial angiogenesis by gene transfer with transplanted cells. Circulation. 2001;104(suppl I):I218-22.

9. Lee RJ, Springer ML, Blanco-Bose WE, Shaw R, Ursell PC, Blau HM. VEGF gene delivery to myocardium: deleterious effects of unregulated expression. Circulation. 2000;22:898-901.

10. Rosenblatt JD, Lunt AI, Parry DJ, Partridge TA. Culturing satellite cells from living single muscle fiber explants. In Vitro Cell Dev Biol Anim. 1995;31:773-9.

11. Wright MJ, Wightman LM, Lilley C, de Alwis M, Hart SL, Miller A, et al. In vivo myocardial gene transfer: optimization, evaluation and direct comparison of gene transfer vectors. Basic Res Cardiol. 2001; 96:227-36.

12. Yap J, O'Brien T, Tazelaar HD, McGregor CG. Immunosuppression prolongs adenoviral mediated transgene expression in cardiac allograft transplantation. Cardiovasc Res. 1997;35:529-35.

13. Kass-Eisler A, Falck-Pedersen E, Elfenbein DH, Alvira M, Buttrick PM, Leinwand LA. The impact of developmental stage, route of administration and the immune system on adenovirus-mediated gene transfer. Gene Ther. 1994;1:395-402.

14. Suzuki K, Murtuza B, Smolenski RT, Sammut IA, Suzuki N, Kaneda $\mathrm{Y}$, et al. Cell transplantation for the treatment of acute myocardial infarction using vascular endothelial growth factor-expressing skeletal myoblasts. Circulation. 2001;104(suppl I):I207-12.

15. Suzuki K, Brand NJ, Allen S, Khan MA, Farrell AO, Murtuza B, et al. Overexpression of connexin 43 in skeletal myoblasts: relevance to cell transplantation to the heart. J Thorac Cardiovasc Surg. 2001;122:75966.

16. Imanishi T, Murry CE, Reinecke H, Hano T, Nishio I, Liles WC, et al. Cellular FLIP is expressed in cardiomyocytes and down-regulated in TUNEL-positive grafted cardiac tissues. Cardiovasc Res. 2000;48: 101-10. 